\title{
HEATING-INDUCED CONVERSION OF Sr-CONTAMINATED BRUSHITE - EXAFS DATA ANALYSIS
}

\author{
E. Rokita, J. ŁażEWski \\ Institute of Physics, Jagiellonian University, Reymonta 4, 30-059 Kraków, Poland \\ C. Hermes and H.-F. Nolting \\ EMBL Outstation Hamburg, c/o DESY, Notkestr. 85, 2000 Hamburg 52, Germany
}

The extended X-ray absorption fine structure method was applied to determine changes of the coordination parameters of $\mathrm{Sr}$ atoms during the thermal conversion of Sr-contaminated brushite into calcium pyrophosphate. The results revealed that the changes of the crystallographic structure induced by heating are correlated with the rearrangement of the $\mathrm{Sr}$ environment. It was also confirmed that $\mathrm{Sr}$ may be used as a marker of $\mathrm{Ca}$ in cases of thermal conversions of orthophosphate groups into pyrophosphate groups.

PACS numbers: 78.70.Dm

It has been shown [1] that the substitution of $\mathrm{Ca}$ by $\mathrm{Sr}$ within calcium phosphates is a compound-dependent process. The results reported so far have dealt with the preparations of Sr-contaminated $\mathrm{Ca}-\mathrm{P}$ compounds produced at a constant temperature. The status of $\mathrm{Sr}$ atoms incorporated into $\mathrm{Ca}-\mathrm{P}$ crystal lattice during thermal treatment of the compound remains unclear.

The problem was investigated using the well-described $[2,3]$ transition of brushite (DCPD $\left.-\mathrm{CaHPO}_{4} \cdot 2 \mathrm{H}_{2} \mathrm{O}\right)$ to calcium pyrophosphate $\left(\mathrm{CPR}-\mathrm{Ca}_{2} \mathrm{P}_{2} \mathrm{O}_{7}\right)$. Brushite, synthesized according to the procedure described previously [4], was heated in air for $8 \mathrm{~h}$ at $500^{\circ} \mathrm{C}$. Such incineration parameters were selected on the basis of our studies of the bone mineralization process [5]. The simplest method to remove the organic matrix from bone samples, i.e. to produce a material useful for the investigations of the structure of the bone minerals, is ashing of the bone samples for $c a .8 \mathrm{~h}$ at $500^{\circ} \mathrm{C}$. Therefore the results obtained are directly correlated with the studies of the bone mineralization process. To prepare Sr-contaminated DCPD the procedure for the synthesis of pure DCPD was modified by adding $\mathrm{Sr}$ ions $(0.5 \mathrm{wt} \%$ of $\mathrm{Ca})$ to a solution containing $\mathrm{Ca}$ ions. The heating procedure was performed for both pure and Sr-contaminated DCPD. The Sr-contaminated compounds were analysed by extended X-ray absorption fine structure spectroscopy 

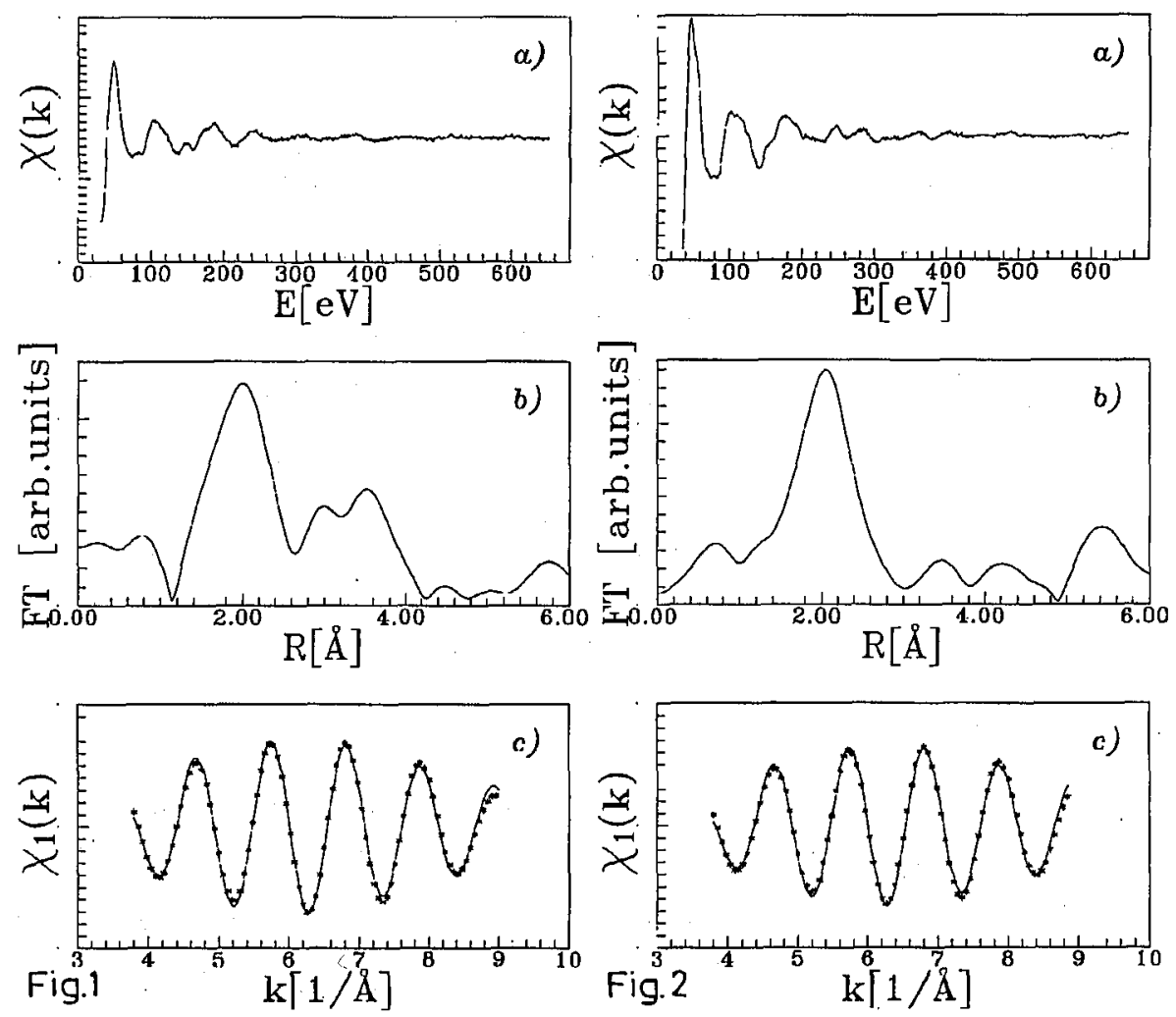

Fig. 1. Results of EXAFS data analysis for $\mathrm{Sr} K$ edge of brushite at liquid nitrogen temperature. (a) $\chi(k)$ EXAFS oscillations, energy zero corresponds to $16106 \mathrm{eV}$; (b) magnitude of Fourier transform of $\chi(k)$ in the range $1 \leq k \leq 10 \AA^{-1}$ using the Hanning window function; (c) the best fit of back Fourier transform taken in the region 1.3-3.0 $\AA$ of the $F(R)$ curve (b).

Fig. 2. Results of EXAFS data analysis for $\mathrm{Sr} K$ edge of $\gamma$-pyrophosphate at liquid nitrogen temperature. (a) $\chi(k)$ EXAFS oscillations, energy zero corresponds to $16106 \mathrm{eV}$; (b) magnitude of Fourier transform of $\chi(k)$ in the range $1 \leq k \leq 10 \AA^{-1}$ using the Hanning window function; (c) the best fit of back Fourier transform taken in the region 1.5-3.3 $\AA$ of the $F(R)$ curve (b).

(EXAFS) at the Sr $K$ absorption edge. Using the EXAFS spectra, the coordination parameters ( $N$ - coordination numbers, $r$ - interatomic distances) of the $\mathrm{Sr}$ atoms were calculated. The thorough description of all experimental methods applied is given elsewhere [1].

The results of the elemental composition studies confirm unequivocally that we were dealing with the compounds in question. No differences between pure and Sr-contaminated compounds are recorded. It should be noted that $\mathrm{Sr} / \mathrm{Ca}$ atomic ratio did not change during heating. It equaled $(1.98 \pm 0.05) \times 10^{-3}$ for DCPD and $(1.96 \pm 0.04) \times 10^{-3}$ for CPR. 
The thermogravimetric data agree with the previously reported results $[2,3]$ and reveal that two thermal transitions took place during heating of brushite to $500^{\circ} \mathrm{C}$. At $180^{\circ} \mathrm{C}$ an anhydrous form (DCP, monetite - $\mathrm{CaHPO}_{4}$ ) is produced which finally transforms at $500^{\circ} \mathrm{C}$ to $\gamma$-CPR. The production of other CPRs ( $\beta$ and $\alpha$ forms) needs heating at higher temperatures $\left(850^{\circ} \mathrm{C}\right.$ and $1200^{\circ} \mathrm{C}$, respectively). The EXAFS data enable a comparison of the coordination parameters of $\mathrm{Sr}$ atoms incorporated into DCPD and $\gamma$-CPR. It should be emphasized that the structure of the $\gamma$-CPR crystals is assumed to be similar to $\beta$-CPR [3]. The only difference is the absence of the $c$-axis regularity characteristic of $\beta$-CPR.

The fine structures of the $\mathrm{Sr} K$ edge collected for both compounds (Figs. 1,2) confirm that $\mathrm{Sr}$ atoms were incorporated into two different systems. The coordination parameters of $\mathrm{Sr}$ atoms are presented in Table. The investigated thermal conversion is related to considerable structural differences between both compounds. DCPD has the $\mathrm{P}$ atom tetrahedrally surrounded by four $\mathrm{O}$ atoms while $\gamma$-CPR contains the pyrophosphate group. The $\mathrm{P}_{2} \mathrm{O}_{7}$ group has two $\mathrm{P}$ atoms which share a bridging $\mathrm{O}$ but are also bonded to three other $\mathrm{O}$ atoms.

The expected substantial differences are not observed as far as the coordination parameiters for the first $\mathrm{O}$ shell (Table) are considered. The $N$ and $r$ values for both structures differ slightly. Probably the only difference results from the removal of one $\mathrm{O}$ atom from the $\mathrm{Sr}$ environment while other $\mathrm{Sr}-\mathrm{O}$ bonds remained unchanged. It is reflected by a decrease in $N$ by about 1 (Table).

TABLE

$\mathrm{Sr}$ coordination parameters calculated from EXAFS spectra. The fitting errors were calculated by the appropriate parameter from its converged value until sum of squares of the residuals reached twice its minimum value. For abbreviations see text.

\begin{tabular}{c|c|c|c}
\hline \hline Atom type & $N$ & $r[\mathrm{~nm}]$ & $\sigma^{2}\left[10^{-2} \mathrm{~nm}^{2}\right]$ \\
\hline \multicolumn{3}{|c}{ brushite } \\
\hline $\mathrm{O}$ & $10.7 \pm 2.4$ & $0.252 \pm 0.003$ & 0.0050 \\
$\mathrm{P}$ & $1.0 \pm 0.2$ & $0.312 \pm 0.004$ & 0.0040 \\
\hline \multicolumn{4}{|c}{$\gamma$-pyrophosphate } \\
\hline $\mathrm{O}$ & $9.6 \pm 1.1$ & $0.256 \pm 0.012$ & 0.0085 \\
$\mathrm{P}$ & $2.8 \pm 0.4$ & $0.332 \pm 0.001$ & 0.0080
\end{tabular}

The major differences between both structures originate from the rearrangement of $\mathrm{P}$ atoms at distances greater than $0.3 \mathrm{~nm}$. It might be expected that the appearance of the pyrophosphate group results in an increase in $N$ for the second $\mathrm{P}$ shell. Moreover, the $\mathrm{Sr}-\mathrm{P}$ bond distances are markedly larger for $\gamma$-CPR than for DCPD, probably because $\mathrm{PO}_{4}$ and $\mathrm{P}_{2} \mathrm{O}_{7}$ are crystallographically independent groups and $\mathrm{Sr}-\mathrm{P}$ distance are governed by the group dimensions.

Summarizing, it may be stated that in case of DCPD- $\gamma$-CPR transition the change of the $\mathrm{Sr}$ coordination is directly correlated with the rearrangement of the crystal structure. Probably the same pertains to all thermal conversions of the $\mathrm{Ca}-\mathrm{P}$ compounds associated with the transition of orthophosphate groups into a 
pyrophosphate group. This conclusion offers a new possibility to use $\mathrm{Sr}$ atoms as markers of $\mathrm{Ca}$ atoms in the experiments dealing with thermal treatment of $\mathrm{Ca}-\mathrm{P}$ compounds.

\section{References}

[1] E. Rokita, C. Hermes, H.-F. Nolting, J. Cryst. Growth 130, 543 (1993).

[2] A.O. McIntosh, W.L. Jablonski, Anal. Chem. 28, 1424 (1956).

[3] H. Catherine, W. Skinner, Mater. Res. Bull. 5, 437 (1970).

[4] T. Moeller, S.J. Bodnar, Inorg. Synth. 4, 20 (1953).

[5] E. Rokita, C. Hermes, H.-F. Nolting, Trace Elem. Med. 9, 136 (1992). 